\title{
Analisa Model Bisnis Radio Suara Surabaya dan Pengembangannya di Era Disruptive Technology
}

\author{
Teguh Santoso*, Jovita Vicka Bayu Wardhani \\ Fakultas Ekonomi, Universitas Katolik Widya Karya, Malang \\ *teguh@widyakarya.ac.id
}

\begin{abstract}
The speed of ICT developments, specifically in internet and mobile technologies, have highlighted the rising importance of the Business Model (BM) in the digital economy era. Digital business is very complex, dynamic and high levels of uncertainty and competition (disruptive). This study analyzes how Radio Suara Surabaya adopts and employs the convergence media in their business activities to anticipate and exploit the opportunity within the disruptive era. The data collection technique uses a mixed methods model Sequential Exploratory Design, where qualitative data includes semi-structured interviews, observations, discusion group focus with stakeholders, while quantitative data includes distributing questionnaires to stakeholders. This study reveal that the adoption of convergence media conducted by Radio Suara Surabaya can maintain their existence within the turbulent business landscape.
\end{abstract}

Keywords : Disruptive Technology, Model Bisnis, Radio Suara Surabaya

\section{PENDAHULUAN}

Pada awal abad ke-20, ketika mobil bertenaga bensin menggantikan kereta kuda, seluruh dunia antusias dalam menyambut datangnya gelombang perubahan pada saat itu, masyarakat agraris beralih menjadi masyarakat industri dan jasa. Saat ini dunia kembali menyaksikan perubahan besar dimana terjadi keruntuhan berbagai perusahaan besar yang telah berpuluh tahun mendominasi pasar seperti Kodak dan Nokia karena proses disrupsi (disruption). Semua kejadian tersebut dipicu oleh makin canggihnya teknologi telekomunikasi dan informasi, khususnya internet.

Internet sebagai jejaring komputer global yang menembus batas telah menciptakan dunianya sendiri. Dunia maya (virtual world) yang tak kasat mata namun ada, dimana lautan data, informasi, maupun pengetahuan diolah, diproses, disimpan, ditransmisikan, dan serentak dihadirkan kembali. Internet berbeda dengan media konvensional sebelumnya, karena ia dapat merengkuh dan menggabungkan citra, gambar-gerak, teks, dan audio-visual (selanjutnya disebut multimedia) secara sempurna dan nyata. Internet membedakan diri dari jenis media sebelumnya yang searah dengan apa yang disebut interaktivitas, konvergen, real-time, dan serba cepat berubah (disruptive).

Salah satu penyedia jasa yang bergerak di bidang elektronik radio di Kota Surabaya adalah Radio Suara Surabaya (SS) FM, dibawah PT Suara Surabaya Media. Radio SS sebagai sarana informasi dan hiburan melihat adanya peluang yang dibutuhkan oleh masyarakat atau pendengar yaitu kebutuhan untuk mendengar radio bukan hanya mendengar dalam komunikasi satu 
arah, melainkan komunikasi dua arah (pendengar berpartisipasi secara aktif).

Melihat peluang tersebut, Radio SS melalui Program Kelana Kota menerapkan komunikasi dua arah dengan mengundang pendengar untuk berperan serta, baik sebagai informan (pemberi informasi) ataupun opinion maker (pembentuk opini), yaitu memberikan informasi tentang traffic report (laporan keadaan lalu-lintas) maupun informasi-informasi atau pendapat lainnya. Sehingga melalui program tersebut, diharapkan akan semakin meningkatkan partisipasi atau peran serta para pendengar sekaligus saling berbagi informasi dan/atau wawasan yang kiranya bermanfaat bagi para pendengar lainnya. Pada titik ini, prinsip saling berbagi (sharing) guna meraih manfaat secara bersama (mutual benefits) mengejawantah.

Berdasarkan pengalaman Radio SS dalam menerapkan komunikasi dua arah melalui Program Kelana Kota, yang kemudian pada era perkembangan teknologi telekomunikasi dan informasi (ICT, information and communication technology), Radio SS melihat peluang dalam penggunaan teknologi internet. Media internet sudah menjadi kebutuhan utama masyarakat untuk memenuhi kebutuhan informasi dan komunikasi, sehingga Radio SS mulai mengaplikasikan pemancar radio melalui media internet, yaitu www.suarasurabaya.net hingga radio streaming yang bisa diakses dimana saja tanpa adanya batasan jarak sebagaimana radio konvensional selama ini. Seorang pendengar di Amerika Serikat, misalnya, bisa menyimak siaran secara langsung dan bahkan bisa berinteraksi pula.

Berdasar uraian tesebut di atas, penelitian ini bertujuan untuk menganalisa bagaimana model bisnis Radio Suara Surabaya dan pengembangannya Di Era Disruptive Technology.

\section{Model Bisnis}

Bila dikilas-balik, konsep dan istilah model bisnis pertama kali mulai dikenal pada tahun 1957. Akan tetapi, konsep ini mulai populer sejak tahun 1990 ke atas, utamanya tatkala model bisnis dikaitkan dengan perubahan lingkungan bisnis serta didiskusikan dalam konteks pesatnya perkembangan teknologi komunikasi dan informasi, khususnya internet beserta segenap aplikasinya dalam kehidupan manusia maupun dunia bisnis khususnya.

Pengertian model bisnis dapat dipilah menjadi 3 (tiga) kelompok yaitu model bisnis sebagai metode atau cara, model bisnis dilihat dari komponen-komponen (elemen), dan model bisnis sebagai strategi bisnis. Pengertian model bisnis sebagai metode, yaitu dimana model bisnis adalah suatu cara untuk menciptakan nilai, sedangkan pengertian model bisnis dilihat dari komponen-komponennya, misalnya adalah model bisnis terdiri dari komponen produk, manfaat dan pendapatan, pelanggan, aset, dan pengetahuan.

Pengertian model bisnis sebagai strategi bisnis adalah model bisnis yang digunakan sebagai alat untuk merumuskan strategi bisnis perusahaan. Secara umum, model bisnis adalah gambaran hubungan antara keunggulan dan sumber daya yang dimiliki oleh perusahaan, serta kegiatankegiatan yang dilakukan untuk mengakuisisi dan menciptakan nilai, yang membuat perusahaan mampu menghasilkan laba (George \& Bock, 2010).

Beberapa elemen atau komponen yang sebaiknya ada di dalam model bisnis (Osterwalder dan Pigneur, 2010): 1) nilai yang dikirimkan kepada pelanggan: customer segments, the value proposition, the spesific "job to be done", what it is sold and what to be sold, 2) dengan cara bagaimana nilai tersebut sampai kepada pelanggan: critical internal resources and processess as well as internal partnership, 3) bagaimana cara mengumpulkan pendapatan: the pricing model and form of monetization, dan 4) Bagaimana posisi perusahaan diantara industri lainnya: the company's role and relationships across the value chain.

\section{Business Model Canvas}

Merujuk pada Osterwalder dan Pigneur (2012: 12), business model canvas (BMC) 
adalah bahasa yang sama untuk mendeskripsikan serta menggambarkan, memvisualisasikan, menilai dan mengubah model bisnis serta memudahkan untuk mengkomunikasikan hal tersebut. Konsep BMC ini bisa menjadi bahasa untuk saling berbagi ide yang memungkinkan anda mendeskripsikan dengan mudah dan memanipulasi model bisnis untuk membuat strategi alternatif baru.

Dengan kata lain, Business Model Canvas adalah suatu alat pembuat model bisnis yang menggambarkan elemen-elemen inti dari sebuah bisnis dengan lebih mudah dalam satu lembar kanvas. Adapun elemenelemen inti tersebut antara lain:

\section{a. Customers Segment}

Dalam menjalankan roda bisnisnya, pertama-tama organisasi harus menetapkan bagian atau jenis pasar mana yang disasar, siapa saja yang akan dilayani. Organisasi dapat menetapkan untuk melayani satu atau lebih segmen. Penentuan segmen pasar atau pelanggan adalah awal sekaligus dasar dari suatu proses pemodelan bisnis karena penetapan segmen ini akan menentukan komponenkomponen lain dalam model bisnis secara menyeluruh.

\section{b. Value Proposition}

Value proposition merupakan tawaran nilai dan manfaat yang ditawarkan organisasi kepada segmen pasar yang dilayani. Tentu saja, value proposition tersebut akan menentukan segmen pelanggan yang dipilih atau sebaliknya, jadi keduanya saling tindak, saling mempengaruhi. Value proposition juga akan mempengaruhi komponen lain seperti Channel dan Customer Relationship. Kecermatan dan kecerdasan dalam memutuskan dan menentukan kedua komponen ini acapkali menentukan keberhasilan dan keberlangsungan (continuity) suatu bisnis.

\section{c. Customer Relationship}

Customer relationship merupakan upaya/cara organisasi menjalin suatu hubungan, ikatan (engagement) dengan pelanggannya dan akan memuncak dalam suatu bentuk kesetiaan (loyalty) pelanggan dan organisasi di masa yang akan datang.

\section{d. Channel}

Channel merupakan suatu sarana dan/atau cara bagi organisasi untuk menyampaikan value proposition kepada customer segment yang dilayani, sekaligus pula menjaga hubungan baik dengan pelanggan. Channel berfungsi dalam beberapa tahapan mulai dari kesadaran pelanggan sampai ke pelayanan purna jual (after sales service). Dua elemen lain yang harus diperhitungkan secara cermat dalam membuat model channel adalah value proposition dan customer segment sebagaimana dipaparkan di atas.

\section{e. Revenue Stream}

Bagian atau komponen model bisnis ini seriang dianggap paling vital karena ibarat darah pemberi kehidupan pada suatu organisasi, tanpanya usaha tidak akan bisa berjalan dengan baik bahkan berujung pada kebangkrutan. Umumnya organisasi memperoleh pendapatan dari pelanggan, meskipun demikian banyak organisasi bisa membuka aliran masuk pendapatan dari kantong bukan pelanggan langsung atau bukan dari usaha utamanya semata (core business). Contoh nyata: Go-Jek, kini tak hanya memperoleh pendapatan dari jasa antar-jemput tetapi juga dari jasa pengiriman, jasa keungan (financial technology), dan sebagainya.

\section{f. Key Resource}

Key resource merupakan sumber daya utama yang merupakan milik organisasi dan digunakan untuk mewujudkan proposisi nilai. Sumber daya umumnya berwujud manusia, teknologi, peralatan, channel maupun brand. Dimana dalam perkembangannya, konsep ekonomi berbagi (sharing economy) telah banyak mengubah pemahaman tentang sumber daya utama untuk tidak lagi sekedar memiliki (owning) tetapi juga saling berbagi (sharing). Hal ini menarik guna menjadi agenda dalam kajian-kajian selanjutnya. 


\section{g. Key Activities}

Key activities merupakan komponen ini adalah suatu kegiatan utama organisasi guna dapat menciptakan dan mewujudkan proposisi nilai suatu organisasi. Tentu saja hal ini tidak bisa lepas dari beragam aktivitas pendukung lainnya yang saling menunjang dan saling melengkapi.

\section{h. Key Partnership}

Key partnership merupakan sumber daya yang diperlukan oleh organisasi untuk mewujudkan proposisi nilai, tetapi tidak dimiliki oleh organisasi tersebut. Dapat pula ia berwujud suatu kemitraan (partnership) yang saling menguntungkan diantara organsisasi dengan pemasoknya (supplier). Pemanfaatan key partnership oleh perusahaan dapat berbentuk outsourcing, joint venture, joint operation, atau aliansi strategis.

\section{i. Cost Structure}

Cost structure merupakan komposisi biaya untuk menggerakkan roda organisasi, mewujudkan proposisi nilai yang dijanjikan kepada pelanggan. Struktur biaya yang efisien, menjadi kunci besarnya laba yang diperoleh organisasi, kendati demikian prinsip dasar efektivitas dan efisiensi hendaklah dikedepankan secara proporsional dan kontekstual tanpa mengurangi kepuasan pelanggan.

Tujuan dari penggunaan Business Model Canvas (BMC) antara lain untuk membangun relasi dengan konsumen agar konsumen kita tidak lari ke pesaing, untuk meningkatkan penjualan, untuk menghadapi pesaing, dan memastikan bisnis berjalan dengan baik dan berkesinambungan, serta untuk membuat sistem bisnis yang lebih efektif (Makinen dan Seppanen, 2010).

\section{Disruptive Technology}

Pada tahun 1997 berkembang istilah disruptive technology yang dikenalkan oleh Clayton M. Christensen seorang Profesor Bisnis dari Harvard Business School menerbitkan buku yang berjudul The Innovator Dillema. Sebagaimana dinyatakan Christensen: "The concept of disruption is about competitive response; it is not a theory of growth, it is adjacent to growth, but it is not about growth itself". Dengan demikian, dapatlah digambarkan bahwa disruptive technology adalah teknologi yang sama sekali baru bukan sekedar kelanjutan dan penyempurnaan teknologi yang ada dan bisa menyebabkan perubahan yang radikal. Adapun beberapa contoh kasus mengenai disruptive technology, seperti : 1) Email, surat elektronik, merupakan disruptive technology untuk direct post (surat biasa), 2) Komputer, adalah disruptive technology bagi mesin ketik, 3) Kamera digital adalah disruptive technology bagi kamera biasa yang memakai film, 4) SMS (Short Messaging Services) adalah disruptive technology bagi pager, 5) PDA/XDA adalah disruptive technology bagi Laptop/PC.

Dari beberapa contoh di atas disruptive technology dapat memainkan peran sebagai pengisi kekosongan dari teknologi yang ada atau menciptakan pasar dan menggantikan pasar dari teknologi yang sudah ada. Hal ini berbeda dengan inovasi. Inovasi lebih kepada perbaikan secara bertahap terhadap teknologi yang sudah ada dalam hal kinerja dari teknologi tersebut.

Adapun 2 kategori disruptive technology (McQuail, 2001), yaitu:

a. Low-end disruption, adalah disrupsi yang mengarah kepada pemakai yang tidak membutuhkan kinerja yang utuh, seperti pemakai yang fanatik yang tingkatannya lebih tinggi. Low-end disruption terjadi ketika tingkat perbaikan produk melampui tingkat kemampuan pemakai untuk mengadopsi kinerja yang baru. Pada tingkatan ini kinerja dari produk telah melampaui kebutuhan dari kelompok pemakai tertentu. Sehingga pada tingkatan ini disruptive technology dapat memasuki pasar dan memberikan produk yang kinerjanya di bawah kinerja yang sudah ada karena produk ini melampaui kebutuhan dari kelompok tertentu.

b. New Market Disruption, adalah disrupsi yang mengarah kepada pemakai yang tidak terakomodasi atau terpusatkan dengan teknologi yang ada. New Market Disruption terjadi ketika produk tidak 
lebih menonjol dalam hal kinerja dibandingkan dengan produk yang sudah ada namun cocok untuk mengisi pasar baru berkembang serta sejalan dengan perkembangan dengan waktu dan inovasi terhadap kinerja produk tersebut. Produk ini akan mengancam pasar bagi produk yang sudah stabil di pasar (incumbent).

\section{METODE}

Penelitian ini menggunakan perpaduan antara metode kuantitatif dan metode kualitatif (mixed method) guna memperoleh gambaran yang lebih menyeluruh akan obyek penelitian. Secara khusus, teknik pengumpulan data menggunakan mixed methods model Sequential Exploratory Design, dimana data kualitatif meliputi wawancara semi terstruktur, observasi, focus grup discusion dengan para stakeholders, sedangkan data kuantitatif meliputi penyebaran kuesioner kepada 50 stakeholders. Stakeholders dalam penelitian ini adalah para pemasang iklan, pihak-pihak penyedia layanan public seperti PDAM-Jasa Marga-Kepolisian dan Pemerintah Kota Surabaya. Keseluruhan proses analisa data yang dilakukan menggunakan pendekatan business model canvas yang setiap building block juga dianalisis dengan SWOT.

\section{HASIL DAN PEMBAHASAN}

Berdasarkan hasil observasi serta hasil survei yang telah dilaksanakan, terdapat beberapa hasil menarik sebagai berikut; pertama, di era digital saat ini, ternyata media komunikasi seperti radio (dalam konteks penelitian ini adalah Radio SS) masih bisa tetap eksis dan digemari oleh publik, terbukti sekitar $60 \%$ merasa terbantu terkait informasi keamanan dan layanan publik khususnya terkait persoalan lalu-lintas dan kriminalitas yang ditayangkan melalui siaran radio SS terkhusus bagian Kelana Kota.

Kedua, konvergensi media (perpaduan antara media digital seperti situs di internet, media sosial seperti Face Book, Twitter, Instagram, dengan media konvensional yakni radio, dalam hal ini Radio SS) adalah suatu hal yang memang dibutuhkan dan disukai oleh responden. Lebih dari $60 \%$ responden menyatakan bahwa mereka beroleh informasi, hiburan, dan pengalaman bermedia yang aktif dan kontruktif (bermanfaat) dengan berparitisipasi dan mengikuti siaran Radio SS sekaligus berperan aktif di media sosial yang terkait (linked) dengan Radio SS yang masih bernaung dalam satu induk organisasi yakni PT Suara Surabaya Media.

Ketiga, dalam konteks Business Model Canvas (BMC) yang sedang dijalankan oleh manajemen dalam menyikapi derasnya era digital yang tak terelakkan dalam bisnis media dewasa ini, terungkap bahwa para penimat (pendengar) Radio SS menilai bahwa konvergensi media digital dan konvensional yang sudah dirintis dan dijalankan selama ini telah memenuhi kebutuhan mereka, khususnya dalam hal updated information (pengkinian informasi) terkait situasi lalu-lintas dan layanan publik di Surabaya dan sekitarnya. Terkait dengan salah satu elemen BMC, ditemukan satu hal menarik yakni cost structure dimana mahalnya iklan dan/atau harga-harga lain yang dikenakan oleh Radio SS dalam kegiatannya ternyata masih bisa diterima karena telah diimbangin dengan kualitas layanan dan content (isi) acara yang berkualitas pula.

Keempat, dari sudut pandang para stakeholders lainnya (yang dimaksud dalam penelitian ini antara lain adalah: para pemasang iklan, pihak-pihak penyedia layanan public seperti PDAM-Jasa MargaKepolisian dan Pemerintah Kota Surabaya umumnya), keberadaan Radio SS beserta konvergensi media yang dijalankan amatlah berguna bagi peningkatan layanan publik di Surabaya dan sekitarnya. Demikian pula halnya dengan persoalan cost structure dinilai oleh para stakeholders bahwa harga yang relatif lebih mahal dibanding radioradio lain tidaklah terlalu menjadi persoalan dikarenakan kualitas layanan dan isi acara/kegiatan yang berkualitas.

Kelima, dari sudut pandang internal organisasi (yakni para karyawan dan 
manajemen Radio SS), pelaksanaan konvergensi media seperti telah dan sedang berjalan, merupakan suatu keniscayaan yang tak terelakkan agar tidak tenggelam diterpa gelombang digitalisasi teknologi. Lebih dari 90\% responden internal sepakat bahwa konvergensi media haruslah dijalankan dengan tidak meninggalkan media konvensional Radio SS yang telah memiliki brand kuat dan digemari oleh masyarakat.

\section{Kesimpulan}

Berdasarkan hasil analisa dan kajian sebagaimana dipaparkan pada bagian terdahulu, terdapat beberapa kesimpulan dari penelitian ini, antara lain : 1) Era disruptive technology yang ditandai secara konkrit dengan maraknya proses digitalisasi di segenap aspek kehidupan merupakan suatu kenyataan yang tak terbantah. Termasuk di dalamnya telah melanda bisnis media, baik cetak maupun elektronik, tak terkecuali bisnis kepenyiaran/radio, 2) Dalam menyikapi kondisi tersebut, jajaran manajemen PT. Suara Surabaya Media, khususnya Radio SS secara terus menerus mengembangkan konvergensi media, baik digital maupun konvensional, melalui berbagai kanal media komunikasi dan berbagai kegiatannya, 3) Keberadaan Radio SS dan konvergensi media yang diterapkan telah diterima dengan baik dan tetap dirasa perlu serta relevan oleh khayalayak penikmat (pendengar radio), para stakeholders, maupun jajaran karyawan (internal) Radio SS sendiri maupun induk organisasinya yakni PT Suara Surabaya Media. 4) Dalam penelitian ini juga terungkap bahwa secara bisnis, khususnya terkait cost structure sebagai salah satu komponen Business Model Canvas (BMC), tetaplah diterima dengan baik meskipun variabel harga yang diterapkan lebih tinggi dibanding media atau radio lain karena telah diimbangi dengan layanan dan konten yang baik.

\section{DAFTAR PUSTAKA}

Amit, R., \& Zott, C. (2001). Value creation in E-business. Strategic Management Journal, 22(6-7), 493-520.
Applegate, L. M. (2001). Emerging Networked Business Models: Lessons from the Field. HBS No. 9-801-172, Harvard Business School, Boston, MA.

Baden-Fuller, C., \& Mangematin, V. (2013). Business models: A challenging agenda. Strategic Organization, 11(4), 418-427.

Creswell, J. W. (2008). Research design: Qualitative, quantitative, and mixed methods approaches ( $3^{\text {rd }}$ ed.). Thousand Oaks, CA: Sage Publications.

Dewobroto, W. S. (2013). Penggunaan Business Model Canvas Sebagai Dasar Untuk Menciptakan Alternatif Strategi Bisnis dan Kelayakan Usaha. Jurnal Teknik Industri issn: 1411-6340. Jakarta: Universitas Trisakti.

Gambardella, A., McGahan, A. M. 2010. Business-Model Innovation: General Purpose Technologies and Their Implications for Industry Structure. Long Range Planning, Vol. 43, No. 2-3, p. 262-271

Høgevold, Nils M.. 2011. A Corporate Effort Towards A Sustainable Business Model. European Business Review, Vol. 23 Iss 4 pp. $392-400$

Jack, S. and Anderson, A. (1999). Entrepreneurship Education Within The Enterprise Culture: Producing Reflective Practitioners. International Journal of Entrepreneurial Behaviour \& Research, Vol. 5 No. 3, pp. 110-25

Kähkönen, Anni-Kaisa. 2012. Value Net: A New Business Model for The Food Industry. British Food Journal, Vol. 114 Iss 5 pp. 681 - 701

Kottler, Philip. and Keller, L. Kevin. 2009. Manajemen Pemasaran, Edisi 13.Terjemahan. Jakarta: Penerbit Erlangga.

Liu, Chun Hsien., Chen, Liu Ming-Chao., Tu, Yi-Hsien., Wang, Chu-Ching. 2014. Constructing A sustainable Service Business Model. International Journal of Physical Distribution \& Logistics Management, Vol. 44 Iss 1/2 pp. 80 - 97 Nahapiet, J. The Role Of Social Capital In Inter-Organizational Relationships. In: CROPPER, S.; EBERS, M.; HUXHAM, 
C.; RING, P. S. (Org.). InterOrganizational Relations. Oxford: Oxford University Press, 2008, P. 580606.

Nahapiet, J. J.; Ghoshal, S. Social Capital, Intellectual Capital, And The Organizational Advantage. Academy Of Management Review, V. 23, N. 2, P. 242-266, 1998

Peter Drucker, 1985. Innovation and Entrepreneurship: Practice and Principles. New York: William Heinemann Ltd. hlm. 67

Peter Smith Ring and Andrew Van de Ven, Developmental Processes of Cooperative Interorganizational Relationships, Academy of Management Review, Vol. 19, No. 1, 1994.

Puspowarsito. AH, 2006, Hubungan Antara Keusahawanan Serikat dengan Prestasi Serikat : Campuran Pemasaran dan Perserikatan Bisnis Sebagai Moderator, Disertasi, Universitas Sains Malaysia (USM).

Roger, Martin L., [i Sally, Osberg (2007) Social Entrepreneurship: The Case for Definition, Leland Stanford Jr. University: 35

Roger.L . Martin \& Sally Osberg. Social Entrepreneurship: The Case For Definition. 2007. Stanford Social Innovation Review. Jr,University.page 34

Ronald S. Burt, Structural Holes: The Social Structure of Competition (Cambridge: Harvard University Press, 1992), p. 12.

Shane, S \& Venkataraman, S, 2000, The Promise of Entrepreneurship as a Fild of Research, Academic Management Review, Vol.25.

Scott A. Snell and James W. Dean, Jr., Integrated Manufacturing and Human Resource Management: A Human Capital Perspective, Academy of Management Journal, Vol. 35, No. 3 (1992), pp. 467-504.

Stoner, A.F, James, et. Al, 2004, Manajemen, Edisi Bahasa Indonesia, Alih Bahasa: Alexander Sindoro, Jakarta: PT Buana Ilmu Populer.
Vasudha Vasakaria. A Study on Social Entrepreneurship and the Characteristics of Social Entrepreneur, The Icfaian Journal of Management Research, Vol. VII, No. 4, 2008. Hlm. 35

Yang, X., Sun, S. L. and Zhao, X. (2018). Search And Execution: Examining The Entrepreneurial Cognitions Behind The Lean Startup Model. Small Business Economics, 1-13.

Yin, R. (2003). K. (2003). Case Study Research: Design And Methods. Sage Publications, Inc, 5, 11.

Yin, R. (1984). Case Study Research. Beverly Hills Ca: Sage.

Yin, R. K. (2013). Validity And Generalization In Future Case Study Evaluations. Evaluation, 19 (3), 321332.

Zott, C., Amit, R. and Massa, L. (2011). The Business Model: Recent Developments And Future Research. 